\title{
ARQUITETURA DO SISTEMA RADICULAR DO PORTA-ENXERTO DE VIDEIRA 'IAC 766' NA ÉPOCA DE TRANSPLANTE DO VIVEIRO PARA O CAMPO'
}

\author{
RICARDO SFEIR DE AGUIAR², CARMEN SILVIA VIEIRA JANEIRO NEVES ${ }^{3}$, SERGIO RUFFO ROBERTO ${ }^{3}$, \\ CRISTIANO EZEQUIEL DOS SANTOS² E WERNER GENTA ${ }^{4}$
}

\begin{abstract}
RESUMO - Na propagação de porta-enxertos de videira por estaquia em recipientes para posterior transplante ao campo, é importante evitar danos ao sistema radicular. O objetivo do trabalho foi determinar, por meio da avaliação da arquitetura do sistema radicular, a melhor fase de desenvolvimento da muda para o transplante, ao campo, do porta-enxerto de videira 'IAC 766' Campinas, em Marialva - PR. As plantas foram avaliadas aos 60; 90; 120; 150 e 180 dias após a estaquia lenhosa em substratos contidos em sacos plásticos de $20 \mathrm{~cm}$ de largura por 30cm de altura. As raízes foram expostas e fotografadas, avaliando-se comprimento e área do sistema radicular pelo programa SIARCS 3.0. Foi utilizado também um diagrama de arquitetura radicular, atribuindo-se notas à conformação do sistema radicular e foi contado o número de raízes enoveladas. O delineamento experimental utilizado foi o de blocos inteiramente ao acaso, com cinco tratamentos e cinco repetições, com 10 plantas por parcela. Os dados foram submetidos à análise de regressão polinomial. Todas as características, com exceção das notas da arquitetura do sistema radicular, ajustaram-se ao modelo de regressão linear crescente. A melhor fase para o transplante da muda do portaenxerto 'IAC 766' para o campo é aos 90 dias após a estaquia.
\end{abstract}

Termos para Indexação: estaquia, Vitis, recipiente, propagação, raiz

\section{ROOT ARCHITECTURE OF IAC 766 GRAPEVINE ROOTSTOCK IN THE TRANSPLANTING FROM THE NURSERY TO THE FIELD}

\begin{abstract}
In grapevine propagation with cuttings in containers it is important to avoid damages to root system during transplanting to the field. The aim of this research was to determine, by means of root system evaluation, the best period to transplant 'IAC 766' (Campinas) rootstock. The trial was set up in July 2004 in Marialva County (PR). The plants were evaluated 60, 90, 120, 150 and 180 days after the establishment of woody cutting in plastic bags of $20 \mathrm{~cm}$ wide and $30 \mathrm{~cm}$ high. The roots were exposed and pictures were taken in lateral and top positions and were evaluated by SIARCS 3.0 software, with determination of the area and the length of the root system. To evaluate the conformation of the root system it was used an architecture diagram attributing scores and counting the number of roots with distortion. The experiment had a randomized complete-block design with ten-plant plots, five treatments and five replications. All characteristics, with exception of the root architecture scores, fitted in a linear crescent regression. The best period for transplanting 'IAC 766' rootstock is around 90 days after the establishment of the cuttings.
\end{abstract}

Index Terms: cutting, Vitis, container, propagation, root system

\section{INTRODUÇÃO}

A produção de uva no Paraná ocorre principalmente na região de Marialva, que representa $45 \%$ do total produzido no Estado (Governo do Paraná, 2003). A produção de uvas finas de mesa nessa região tem-se destacado no desenvolvimento e adoção de tecnologias adaptadas às condições locais (Genta, 2000). O portaenxerto mais utilizado para a cultivar Itália e suas mutações é o 'IAC 766' por apresentar adaptação às condições ambientais, resistência a doenças, bom índice de pegamento na estaquia e elevado vigor. O método mais usado na propagação da videira em pomares comerciais é a estaquia lenhosa do porta-enxerto durante o inverno no local definitivo, complementada pela enxertia da variedade-copa um ano após o plantio (Rezende \& Pereira, 2001), mas o uso de estaquia em recipientes e posterior transplante para o local definitivo vem aumentando por permitir a realização da enxertia no mesmo ano, obtendo-se a muda enxertada em menos de um ano (Pires \& Biasi, 2003). Na região de Marialva, esse sistema tem sido cada vez mais empregado.

Quando as mudas de videira são produzidas em recipientes, apresentam maior proporção de raízes enoveladas próximas ao tronco em razão da limitação oferecida pelos recipientes ao desenvolvimento radicular, principalmente para as cultivares mais vigorosas (Bordin et al., 2003). Este fato é importante a ser considerado no planejamento e plantio dos pomares, sendo que os porta-enxertos mais vigorosos devem ficar menos tempo nos recipientes antes do plantio ao local definitivo. Entre os problemas que podem ser causados pelas deformações do sistema radicular, destaca-se a interferência na partição de carboidratos, na produção e transporte de reguladores de crescimento e na absorção de água e nutrientes, sendo que estes problemas tendem a se intensificar em períodos de deficiência hídrica (Richards, 1983; Hellman, 2003).

Como as deformações causadas nas raízes dos porta-enxertos de videira plantadas em recipientes na fase de viveiro podem prejudicar a conformação do sistema radicular das plantas adultas depois do plantio no local definitivo, é de fundamental importância para os produtores determinarem a melhor fase de desenvolvimento da muda para o transplante a campo de forma a evitar tais deformações.

Assim, o presente trabalho teve como objetivo avaliar a arquitetura do sistema radicular de mudas do porta-enxerto de videira 'IAC 766' em diferentes fases do seu desenvolvimento no viveiro, determinando-se a melhor época para o transplante a campo, na região de Marialva, Paraná.

\section{MATERIAL E MÉTODOS}

O experimento foi estabelecido nos dias 21 e 22 de julho de

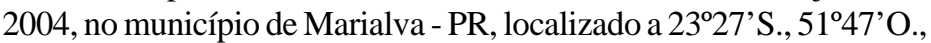
altitude de $600 \mathrm{~m}$. As temperaturas durante o trabalho (2004-2005), obtidas na estação meteorológica do Instituto Tecnológico Simepar em Maringá, acerca de $20 \mathrm{~km}$ do experimento, foram as seguintes:

\footnotetext{
(Trabalho 58-2006). Recebido: 08-05-2006. Aceito para publicação: 25-08-2006.

${ }^{2}$ Eng $^{\circ}$ Agr ${ }^{\circ}$. Mestrando em Agronomia, Universidade Estadual de Londrina, PR. Bolsista da CAPES. C.P. 6001. CEP 86051-990 Londrina - PR. e-mail: rsaguiar@hotmail.com

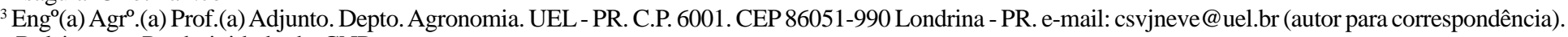
Bolsista em Produtividade do $\mathrm{CNPq}$.

${ }^{4}$ Eng $^{\text {o. }}$ Agr $^{\circ}$,Associação Norte Paranaense de Estudos em Fruticultura (ANPEF), Marialva - PR
} 
mínimas, médias e máximas mensais, respectivamente $\left(\mathrm{em}^{\circ} \mathrm{C}\right)$ : julho: 13,$7 ; 17,4 ; 21,4$; agosto: 15,$3 ; 20,8 ; 26,7$; setembro: 20,$1 ; 24,9 ; 30,2$; outubro: 16,$9 ; 21,6 ; 26,9 ;$ novembro: 18,$7 ; 23,2 ; 28,0 ;$ dezembro: 19,8 ; 24,0; 28,5; janeiro: 21,$1 ; 23,9 ; 27,8$.

Os porta-enxertos foram propagados por estaquia, em sacos plásticos pretos de $20 \mathrm{~cm}$ de largura por $30 \mathrm{~cm}$ de altura, com capacidade de aproximadamente $2 \mathrm{~kg}$ de substrato e com furos na base. O substrato utilizado foi uma mistura de solo de barranco (Latossolo Vermelho distroférrico de textura muito argilosa), calcário $3,0 \mathrm{~kg} \cdot \mathrm{m}^{-3}$, fosfato natural de Arad (com 28-33\% de $\mathrm{P}_{2} \mathrm{O}_{5}$ total) $5,0 \mathrm{~kg} \cdot \mathrm{m}$ ${ }^{3}$ e esterco $100 \mathrm{~L} . \mathrm{m}^{-3}$. Foram utilizadas estacas lenhosas do portaenxerto 'IAC 766' (Campinas) obtidas do viveiro Fruticafé, no próprio Município. As estacas foram preparadas com $25-30 \mathrm{~cm}$ de comprimento, aproximadamente $5 \mathrm{~cm}$ de diâmetro e cinco gemas. $\mathrm{O}$ corte da base das estacas foi feito acima do nó, e o do ápice, a 3-4 cm acima da gema superior para evitar o seu dessecamento. Foram eliminadas as gemas basais para facilitar o enraizamento e evitar a emissão de ramos abaixo da superfície do solo.

As estacas foram colocadas para enraizar nos recipientes plásticos previamente preenchidos com o substrato, sendo enterradas em aproximadamente $50 \%$ de seu comprimento, sem deixar que a sua base tocasse o fundo dos recipientes. Os recipientes foram colocados em viveiro a pleno sol, recebendo irrigação quando necessário.

As estacas permaneceram nos recipientes plásticos por 60; 90; 120; 150 e 180 dias, que correspondem às épocas de avaliação. Para isso, as plantas foram removidas do viveiro e levadas ao Setor de Fruticultura da Universidade Estadual de Londrina, onde foram retiradas dos recipientes e lavadas. Para as avaliações, foram utilizadas apenas as mudas que apresentaram enraizamento, que representaram $96,8 \%$ do total, descartando-se as demais.
Para a análise das raízes, as mudas foram suspensas para que seus sistemas radiculares fossem fotografados nas posições lateral e superior. As fotografias foram avaliadas pelo Sistema Integrado de Análise de Raízes e Cobertura do Solo (SIARCS 3.0) (Crestana et al., 1994), obtendo-se o comprimento total e a área total de projeção das raízes.

Para avaliar a arquitetura do sistema radicular, foi utilizado um diagrama de notas (Mason, 1985), no qual a nota 0 foi a melhor e a nota 13 a pior conformação (Tabela 1). Analisou-se, também, a freqüência de raízes enoveladas, contando-se o total de raízes e determinando-se a porcentagem das raízes com enovelamento em espiral (Bordin et al., 2003).

O delineamento experimental utilizado foi o de blocos inteiramente ao acaso, com cinco tratamentos e cinco repetições. Cada parcela foi constituída por dez mudas. Os dados foram analisados pelo programa Sisvar ${ }^{\circledR}$, empregando-se análise de regressão.

\section{RESULTADOS E DISCUSSÃO}

As características de comprimento das raízes ajustaram-se ao modelo de regressão linear, havendo um aumento de 239,62 cm aos 60 dias para 556,21 cm aos 180 dias após a estaquia para o comprimento total na vista lateral, e um acréscimo de 321,72 para $733,97 \mathrm{~cm}$ entre as avaliações realizadas aos 60 e 180 dias na vista superior (Figura1). Resultados semelhantes foram conseguidos por Biasi et al. (1998), que, utilizando estacas lenhosas propagadas em recipientes do porta-enxerto 'IAC 766', obtiveram um aumento de $175 \mathrm{~cm}$ aos 90 dias para $1.900 \mathrm{~cm}$ aos 276 dias. Os autores observaram também que o crescimento começou a se estabilizar por volta dos 210 dias, em razão do limite imposto pelo tamanho do recipiente.

TABELA 1- Escala de referência da arquitetura do sistema radicular, para avaliação das deformações apresentadas pelas raízes, observadas em vista lateral (adaptado de MASON, 1985):

\section{Notas \\ Descrição do sistema radicular}

0 As raízes saem dos quatro quadrantes da base da estaca e não apresentam deformações.

1

2

3

4

5

6

7

8

9

10

11

12

13
As raízes saem dos quatro quadrantes da base da estaca e apresentam deformações em apenas um quadrante.

As raízes saem dos quatro quadrantes da base da estaca e apresentam deformações em dois quadrantes.

As raízes saem dos quatro quadrantes da base da estaca e apresentam deformações em três quadrantes.

As raízes saem dos quatro quadrantes da base da estaca e apresentam deformações nos quatro quadrantes.

As raízes saem de três quadrantes da base da estaca e não apresentam deformações.

As raízes saem de três quadrantes da base da estaca e apresentam deformações em apenas um quadrante.

As raízes saem de três quadrantes da base da estaca e apresentam deformações em dois quadrantes.

As raízes saem de três quadrantes da base da estaca e apresentam deformações nos trêsquadrantes.

As raízes saem de dois quadrantes da base da estaca e não apresentam deformações.

As raízes saem de dois quadrantes da base da estaca e apresentam deformações em apenas um quadrante.

As raízes saem de dois quadrantes da base da estaca e apresentam deformações nos dois quadrantes.

As raízes saem de um quadrante da base da estaca e não apresentam deformações.

As raízes saem de um quadrante da base da estaca e apresentam deformações em apenas um quadrante. 

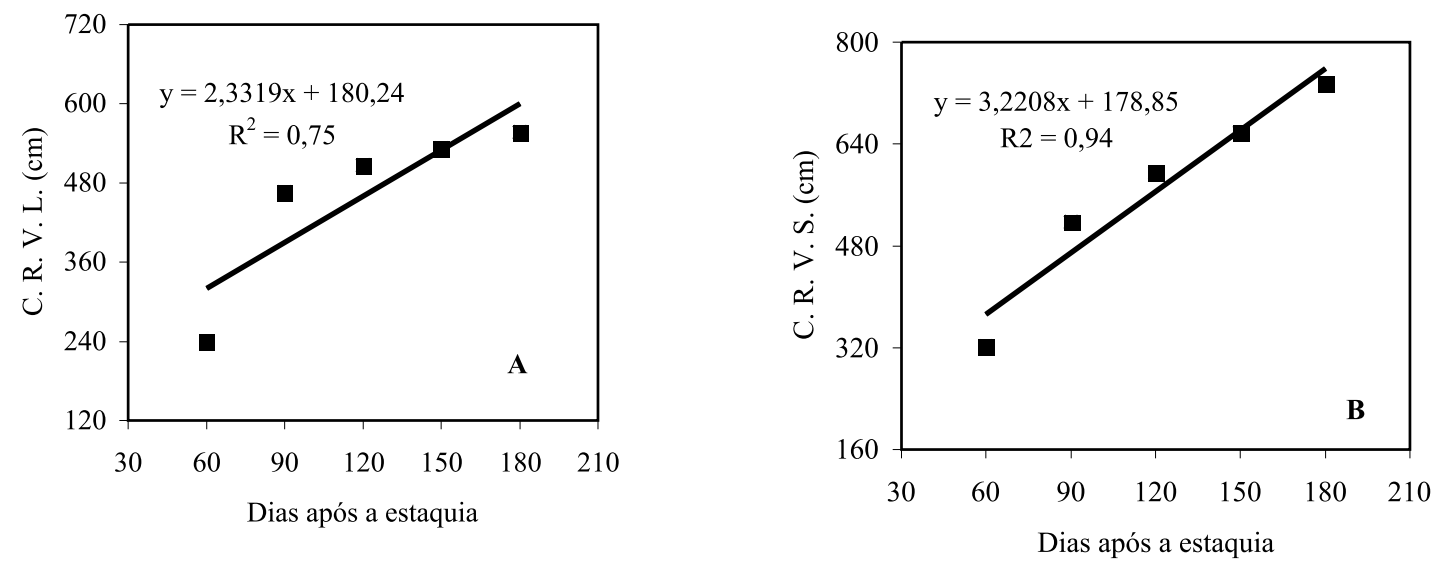

FIGURA 1 -Evolução do comprimento das raízes através da vista lateral (C.R.V.L.) (A) e do comprimento das raízes através da vista superior (C.R.V.S.) (B) do porta-enxerto de videira 'IAC 766', em função do período após a estaquia. Marialva-PR.
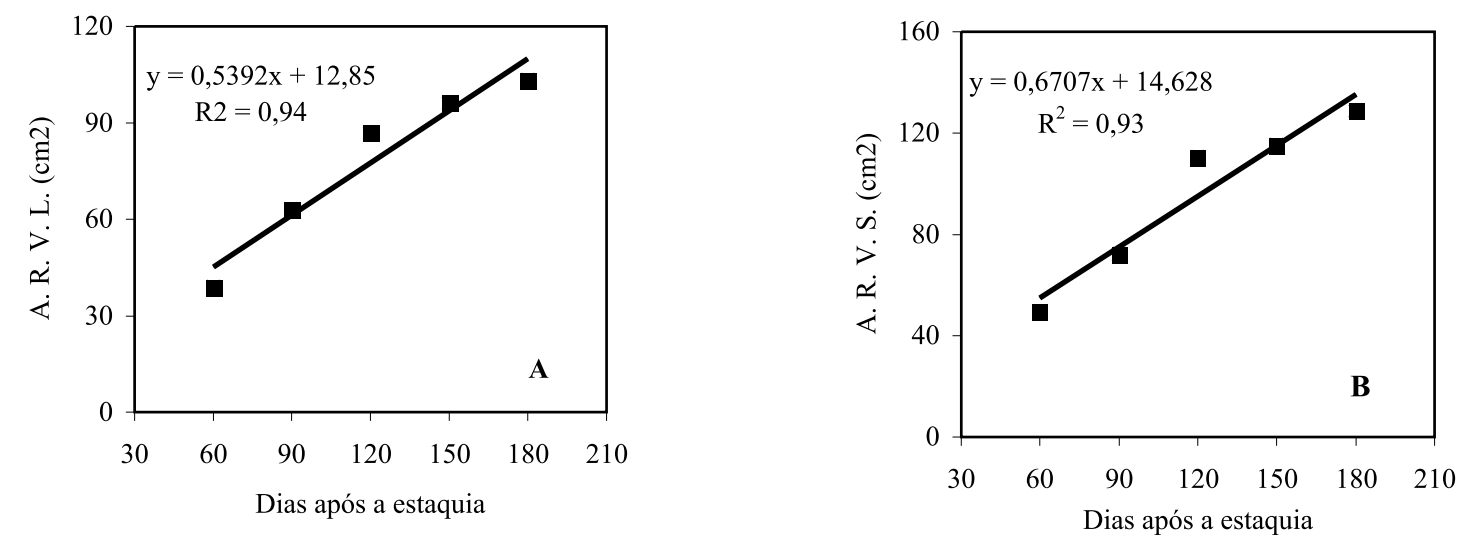

FIGURA 2 - Evolução de área das raízes através da vista lateral (A R.V.L.) (A) e da área de raízes através da vista superior (A.R.V.S.) (B) em, do porta-enxerto de videira 'IAC 766', em função do período após a estaquia. Marialva-PR.
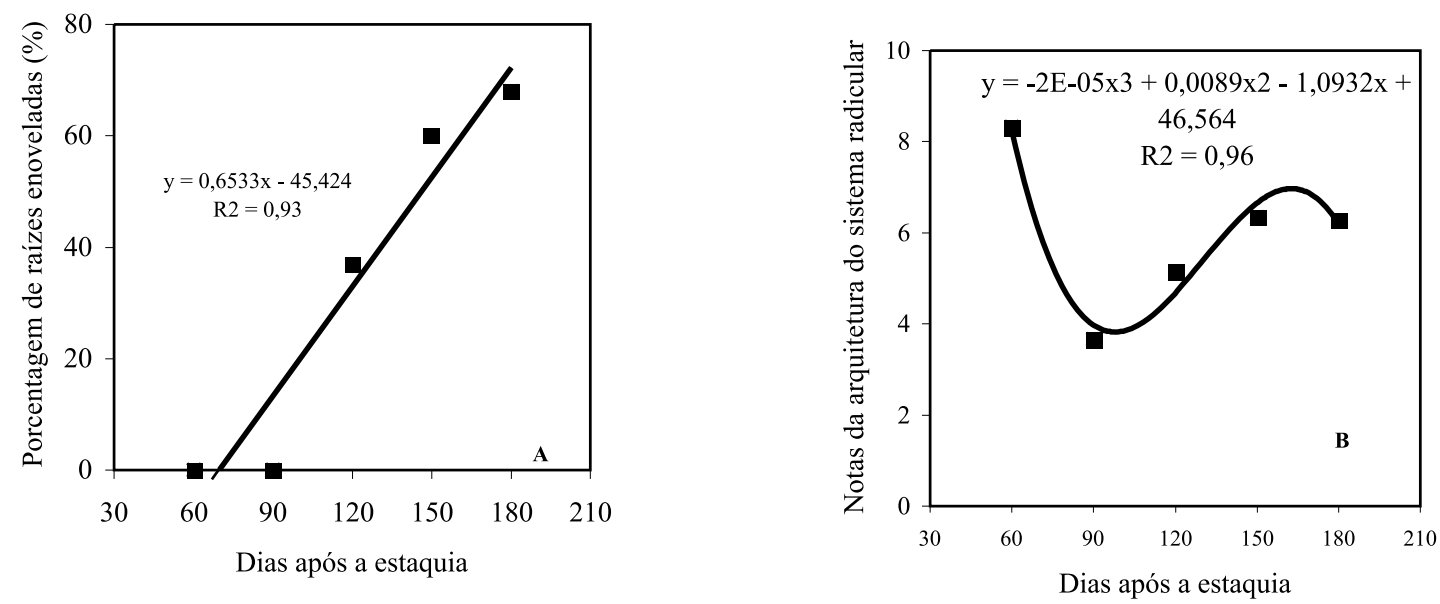

FIGURA 3 - Evolução de porcentagem de raízes enoveladas (A) e das notas da arquitetura do sistema radicular (B), do porta-enxerto de videira 'IAC 766', em função do período após a estaquia. Marialva-PR.

Leão (2003) obteve resultados semelhantes utilizando estacas lenhosas do porta-enxerto 'IAC 572', obtendo um comprimento de $358,3 \mathrm{~cm}$ aos 60 dias.

A área de projeção total das raízes nas vistas lateral e superior ajustou-se ao modelo de regressão linear, havendo um aumento de $38,95 \mathrm{~cm}^{2}$ na primeira avaliação para $103,19 \mathrm{~cm}^{2}$ na última avaliação para a vista lateral, e de $49,47 \mathrm{~cm}^{2}$ para $128,60 \mathrm{~cm}^{2}$ para a vista superior (Figura 2). Os resultados obtidos são concordantes com os obtidos por Mendonça (1994), que comprovou o ótimo enraizamento do porta-enxerto 'IAC 766' em recipientes, quando comparado com outras cultivares e híbridos. A grande extensão apresentada pelo sistema radicular do porta-enxerto 'IAC 766' pode ser muito útil em condições de falta de água no solo, por permitir às plantas a exploração de um maior volume do solo, reduzindo o estresse hídrico, que é caracterizado pelo fechamento dos estômatos, e conseqüente diminuição da difusão de $\mathrm{CO}_{2}$ para o mesófilo foliar (Souza et al., 2001).

Para a evolução da porcentagem de raízes enoveladas (Figura 3), aos 60 e 90 dias, as mudas não apresentaram nenhuma raiz enovelada. Nas três avaliações seguintes, observou-se enovelamento, com 37; 60 e 68\% de raízes enoveladas aos 120; 150 e 180 dias após a estaquia, respectivamente. 
Para as notas da arquitetura do sistema radicular, observa-se que esta característica se ajustou ao modelo de regressão cúbica. A menor nota, isto é, 3,66, que representa o melhor desempenho, ocorreu aos 90 dias após a estaquia, quando ainda não havia ocorrido o enovelamento de raízes (Figura 3). A maior nota, ou seja, 8,32 , ocorreu aos 60 dias, quando, apesar de não apresentarem raízes enoveladas, as mudas possuíam muitas raízes pequenas e que não saíam de todos os quadrantes da base da estaca, o que poderia prejudicar o desempenho da muda no campo. Isto significa que as raízes das mudas, aos 60 dias, ainda não tinham alcançado seu pleno desenvolvimento, que ocorreu aos 90 dias após a estaquia. Nas avaliações posteriores, aos 120; 150 e 180 dias, as notas obtidas pelo sistema radicular mantiveram-se acima de 5, o que caracteriza a existência de deformações (Tabela 1).

Assim, ainda que as raízes continuassem a se desenvolver linearmente durante todo o período avaliado (Figuras 1 e 2), o limite imposto pelo recipiente a partir dos 90 dias após a estaquia prejudicou a arquitetura radicular, provocando deformações e enovelamentos. Essas deformações causadas pelos recipientes na fase de viveiro podem prejudicar a conformação do sistema radicular das plantas adultas depois do plantio no local definitivo (Neves et al., 2005). Essas características devem ser levadas em consideração na ocasião do transplante da muda do viveiro para o campo, principalmente para os porta-enxertos mais vigorosos como o 'IAC 766', pois estes devem ficar menos tempo nos recipientes antes do plantio no local definitivo.

Na região de Marialva - PR, para contornar o problema do enovelamento dos porta-enxertos produzidos em recipientes plásticos, os viticultores normalmente realizam o toalete, que consiste no corte das raízes enoveladas no momento do transplante da muda do viveiro para o campo. Entretanto, tal procedimento pode ser uma via de entrada de doenças, além de reduzir o volume de raízes, o que pode prejudicar o pegamento da muda. Nesta região, onde a maioria dos produtores realiza a formação dos seus vinhedos utilizando mudas obtidas por estaquia lenhosa em recipientes, é fundamental o conhecimento da fase ideal do transplante da muda do viveiro para o campo para que não ocorram injúrias ao sistema radicular dos porta-enxertos. Dessa forma, no planejamento do pomar, deve-se considerar que o transplante para o local definitivo do porta-enxerto 'IAC 766' deva ser feito cerca de 90 dias após a estaquia, quando empregados os recipientes citados neste trabalho.

\section{CONCLUSÕES}

A melhor fase para transplante do porta-enxerto 'IAC 766' do viveiro para o campo, na região de Marialva - PR, é aos 90 dias após a estaquia lenhosa, quando usados recipientes de $2 \mathrm{~kg}$ de capacidade.

\section{REFERÊNCIAS}

ANUÁRIO estatístico do Paraná 2003. Curitiba: IPARDES, 2002. Disponível em: <http://www.pr.gov.br/ipardes/pdf/ anuario_2003/economico/uva.PDF>. Acesso em: 3 maio 2004.

BIASI, L. A.; POMMER, C. V.; PASSOS, I. R. da S. Crescimento de porta-enxertos de videira por estaquia e por micropropagação em minirrizotrons. Ciência e Agrotecnologia, Lavras, v.22, n.4, p.556-564, 1998.

BORDIN, I.; NEVES, C. S. V. J.; AZEVEDO, M. C. B. de. Arquitetura e dimensão do sistema radicular de sete porta-enxertos de videira no Norte do Estado do Paraná. Revista Brasileira de Fruticultura, Jaboticabal, v.25, n.3, p.526-527, 2003.

CRESTANA, A.; GUIMARÃES, M. F.; JORGE, L. A. C.; RALISCH, R.; TOZZI, C. L., TORRES, A.; VAZ, C. M. P. Avaliação da distribuição de raízes no solo auxiliada por processamento de imagens. Revista Brasileira de Ciência do Solo, Viçosa, v.18, p.365-371, 1994.

GENTA, W. A cultura da videira. Marialva: PLANTA- Planejamento e assistência técnica. 2000. 19p.

HELLMAN, E. W. Grapevine Structure and Function. In: HELLMAN, E. W. (Ed.). Oregon Viticulture. Corvallis: Oregon State University Press, 2003. p.5-19.

LEÃO, P. C. de S. Utilização de diferentes tipos de estaca na produção de mudas do porta-enxerto de videira, cv. IAC 572 'Jales'. Ciência Rural, Santa Maria, v.33, n.1, p.165-168, 2003.

MASON, E. G. Causes of juvenile instability of Pinus radiata on ripped and unripped taupo pumice soil. New Zealand Journal of Forestry of Science, Rotorna, v.15. n.3, p.263-280, 1985.

MENDONÇA, R. M. N. Viabilidade da formação de mudas de videira cultivar Niagara Rosada ( Vitis labrusca L.X Vitis vinifera $\mathbf{L}$.) em recipiente. 1994. 71f. Dissertação (Mestrado) - Faculdade de Ciências Agrárias e Veterinárias, Universidade Estadual Paulista, Jaboticabal, 1988.

NEVES, C. S. V. J.; MEDINA, C.de C.; AZEVEDO, M. C. B. de; HIGA, A. R.; SIMON, A. Efeitos de substratos e recipientes utilizados na produção de mudas sobre a arqutetura do sistema radicular de árvores de acácia-negra. Revista Árvore, Viçosa, v.29, n.6, p.897-905, 2005.

PIRES, E. J. P.; BIASI, L. A. Propagação da videira. In: POMMER, C. V. Uva: tecnologia da produção, pós-colheita e mercado. Porto Alegre: Cinco Continentes, 2003. p.295-350.

REZENDE, L. DE P.; PEREIRA, F. M. Produção de mudas de videira 'Rubi' pelo método de enxertia de mesa em estacas herbáceas dos porta-enxertos IAC 313 'Tropical' e IAC 766 'Campinas'. Revista Brasileira de Fruticultura, Jaboticabal, v.23, n.3, p.662667, 2001.

RICHARDS, D. The grape root system. Horticultural Reviews, Victoria, v.5, p.127-168, 1983.

SOUZA, C. R.; SOARES, A. M.; REGINA, M. A. Trocas gasosas de mudas de videira, obtidas por dois porta-enxertos, submetidas à deficiência hídrica. Pesquisa Agropecuária Brasileira, Brasília, v.36, n.10,p. 1.221-1.230, 2001. 